\title{
Procedural skills and neurobehavioral freedom
}

\author{
Nerea Crespo-Eguílaz, Sara Magallón and Juan Narbona* \\ Pediatric Neurology Unit and Department of Education, University of Navarra, Pamplona, Spain \\ *Correspondence: jnarbona@unav.es \\ Edited by: \\ Jose Angel Lombo, Pontifical University of the Holy Cross, Italy \\ Reviewed by: \\ Gerry Leisman, O.R.T.-Braude College of Engineering, Israel
}

Keywords: attention, central coherence, developmental coordination disorder, implicit memory, operational habit, pragmatics, procedural learning, social communication disorder

\section{INTRODUCTION}

Procedural learning (PL) is a part of implicit memory (Shiffrin and Schneider, 1977) and is based on brain subsystems of associative cortex and its connections with basal ganglia and cerebellum (Squire, 1992). PL gives the human individual a gain in freedom: automatic healthy cognitive and motor skills help to save an important amount of conscious work in daily routines and in effortful cognitive and/or motor action (Treisman and Gelade, 1980; Kahneman et al., 1983). In this way, attention can be focused on quick understanding, central coherence awareness, problem-solving processes and social accuracy. Human procedural skills and executively-controlled aspects of action intersect and cooperate with each other (Leisman et al., 2014). Useful procedural automatisms are basically acquired during childhood and youth, but also over the whole course of life, by means of incidental experience and by formal education. PL enhances the natural potentialities (i.e., predispositions) of the agent for a suitable unfolding of his or her operations. From this point of view, acquired automatisms could be included among operational habits in the interface between perceptual-motor and cognitive-volitional human activities.

\section{DEVELOPMENTAL COORDINATION DISORDER: AN EXPANDED VIEW}

There is a child population for which operational habit learning is particularly difficult. Clumsiness, disproportionate to general development, is the most evident characteristic of individuals with this developmental condition, which has been labeled developmental dyspraxia and, more recently, developmental coordination disorder (DCD). At present, the most widely accepted definition of DCD in childhood comes from the Diagnostic and Statistical Manual of Mental Disorders, IVth and 5th editions (APA-American Psychiatric Association, 2000, 2013) and from the International Classification of Diseases-11th edition draft (World Health Organisation, 2013). DCD is essentially regarded as a disturbance of motor coordination, which consequently is substantially below that expected given the child's age and intelligence, but this is not due to a general medical condition (e.g., cerebral palsy) and does not meet the criteria for a pervasive developmental disorder; if mental retardation is present, motor difficulties exceed those expected for the level of mental development. DCD causes disruption of daily living activities and academic achievement. DCD is estimated to affect to $2-8 \%$ of schoolchildren (Kadesjö and Gillberg, 1998; Crespo-Eguílaz and Narbona, 2009; Lingam et al., 2009; Missiuna et al., 2011).

Young people with DCD have a characteristic slowness in daily routines. They are disproportionately unskilled not only for motor actions, as can be measured using ad-hoc scales and batteries (Bruininks and Bruininks, 2005; Henderson and Sugden, 2007; Wilson et al., 2009) but also for quick perceptual management of complex visuospatial information and motor imagery (Noten et al., 2014). Moreover DCD has a high comorbidity with attention deficit / hyperactivity disorder (ADHD), and with social communication (language pragmatic) disorder (Gillberg, 2003; Crespo-Eguílaz and Narbona, 2009; Crespo-Eguílaz et al., 2012; American Psychiatric Association,
DSM-5, 2013; World Health Organisation, IDC-11 draft, 2013). As a consequence, affected children and adolescents typically behave in a naïve manner, and their social use of language is frequently inaccurate (Volden, 2004; Crespo-Eguílaz and Narbona, 2009; Brossard-Racine et al., 2011; Westendorp et al., 2011; Blank et al., 2012). All these impairments have a significant negative impact on activities of daily living, such as, dressing, handwriting, sports, and social exchanges (Blank et al., 2012). Depression, anxiety, and risk of bullying by peers are significantly more frequent in children with DCD and those with comorbid DCD and ADHD vs. typical controls (Zwicker et al., 2012; Missiuna et al., 2014).

\section{PROCEDURAL LEARNING IN CHILDREN WITH DEVELOPMENTAL COORDINATION DISORDER: SOME EXPERIMENTAL EVIDENCE}

A variety of dysfunctions of neural loops relating prefrontal, secondary premotor and parietal cortices, with basal ganglia and cerebellum, have been proposed (Bo and Lee, 2013; Leisman et al., 2014) to explain the physiopathology of DCD.

In a continuous task with implicit visual sequences, schoolchildren with DCD learn poorly relative to typically developing children. Children with DCD demonstrated a general learning of visuo-perceptive task demands that was comparable to that of controls, but they failed to learn anticipation of implicit visuo-motor sequences. Interestingly, a sequence recall test, administered after the whole task, indicated some awareness of the repeating sequence pattern (Gheysen et al., 2011). By contrast, using the same paradigm, Lejeune et al. (2013) found no 
evidence of a difference in performance between children with DCD and typically developing children.

In order to assess PL in children with $\mathrm{ADHD}, \mathrm{DCD}$ and reading learning disorder (RD), Magallón et al. (submitted) tested the children with two implicit / procedural learning tasks using the Purdue pegboard (Gardner and Broman, 1979) and an adaptation of the mirror drawing task (Milner et al., 1968). Participants aged 6-12 years old were classified into four groups matched for gender, age and severity of ADHD symptoms: 19 children with ADHD only, 30 children with DCD+ADHD, 48 children with $\mathrm{RD}+\mathrm{ADHD}$, and 90 typically developing children. All participants accomplished three consecutive trials of each of the two tasks and a delayed fourth trial following a verbal interference task. Typicalfor-age scoring measures of performance were compared (Student's $\mathrm{t}$ ) within trials and between groups. The baseline results of the DCD+ADHD group were significantly lower than those of the other groups. Nevertheless, after three repetitions of the two tasks, DCD+ADHD children improved their efficiency and reached that of the baseline of both the nonDCD clinical groups. This learned performance was retained at the delayed fourth trial. However, the percentage improvement obtained by DCD children was lower than that of the other two clinical groups and controls in all the trials.

Another study (Crespo-Eguílaz et al., 2012) addressed the ability of schoolchildren to quickly grasp and verbally explain "nonsense" in complex figurative pictures: a chimeric figure and an absurd scene. Only $11.3 \%$ of schoolchildren with DCD and with DCD+ADHD resolved the tasks accurately, whereas $87.5 \%$ of controls and ADHD-alone children did these two central coherence function tasks successfully (chi-square test: $p<0.01$ ).

As mentioned above, children with DCD + ADHD also usually have difficulties integrating inputs of complex visual or verbal information. As a consequence, they struggle to get the whole picture, miss relevant clues in social contexts, have problems dealing with inference, and fail to make sense of figurative language, jokes, narratives and adapted conversation. These psycholinguistic difficulties are reminiscent of the characteristics of Social (pragmatic) Communication Disorder (SCD) as defined in DSM-5 and in ICD11 draft. So, we might ask whether DCD is typically comorbid with SCD. An alternative explanation would be that pragmatic difficulties are a part of DCD. To investigate this question, a Spanish translation of the Children's Communication ChecklistCCC (Bishop, 1998) was given to the parents of children aged 6-12 years who were divided into five groups: those with DCD+ADHD, those with ADHD only, those with SCD, those with high functioning autism spectrum disorder (HFASD), and those with typical development (Narbona et al., in press). The five groups were matched for mental age and gender. The results suggest that communication difficulties in children with DCD $+A D H D$ are qualitatively different, more severe and have a larger impact on social relationships than those shown by children with ADHD only. On the other hand, the pragmatic difficulties in children with DCD+ADHD are milder than those defining SCD and HFASD. Moreover the HFASD group showed unusual, restricted and stereotyped interests. In contrast, $\mathrm{DCD}+\mathrm{ADHD}$ and SCD groups do not have a characteristic restriction of interests, and their basic social motivation and abilities are preserved, apart from the linguistic difficulties. These results are in accordance with recent research reviews (Gibson et al., 2013; Norbury, 2014).

Pragmatic difficulties may be present in children with ADHD, developmental coordination disorder, autism spectrum disorders, Williams syndrome, spina bifida with hydrocephalus, cerebral palsy, etc. (Holck et al., 2009); thus pragmatic difficulties can be either a component of several large behavioral phenotypes or an isolated communication disorder (i.e., SCD, as it has been recently proposed in DSM-5 and in ICD-11 draft). Given that children with DCD most frequently have pragmatic difficulties, it would seem that these are not comorbid but constitute a component of DCD related to the failure to grasp visuospatial clues useful in evaluating social appropriateness. In contrast, pragmatic communication difficulties of autistic persons are included in their social/intersubjective pervasively disordered abilities (Norbury, 2014).

\section{DISCUSSION AND CONCLUDING REMARKS}

We propose that the core dysfunction in DCD affects procedural learning. PL deals not only with motor skills but also with fast perceptive integration, cognitive routines and socially accurate habits. As a consequence, children with DCD are characterized by slowness not only for motor tasks but also for awareness of relevant cognitive and social clues, which causes difficulties in contextualizing information and in social relationships with peers. Children with DCD do have normal intersubjective skills and a normal desire to communicate with other people, in contrast to children with autistic spectrum disorders (Norbury, 2014). The above-mentioned experimental results on procedural learning of visual sequences, of mirror drawing, of motor manual skills and of quick verification of central coherence, suggest that a basic neuropsychological dysfunction of procedural learning may be the central problem in DCD, with its frequent association to social communication disorder. This basic PL dysfunction seems to be intrinsic to DCD and independent of attention deficit: the experiments took account of attention deficit by considering a group of subjects with ADHD alone.

A limitation of the above experimental studies is that the tasks were highly specific. Similar studies with larger samples, with more diverse and ecological tasks, and with greater number of trials (to justify the assumption of long-term learning), are necessary.

Children with DCD can improve their motor and cognitive performance by repetition. Therefore, we suggest that this developmental condition does not imply an absolute inability, but a poor natural disposition, to learn motor and/or cognitive facilitating strategies. Assuming, as indicated by the research findings, that the core dysfunction lies in automation, an appropriate approach to help affected children would be to base intervention on repetition of the skills needed by each individual patient in his or her everyday ecological context and taking account of personal motivations and preserved abilities (for example, language for autoinstructions). 
The persistent nature of DCD in around one-half of individuals first diagnosed in childhood (Cantell et al., 1994) emphasizes the importance of occupational therapy intervention in youth. The majority of approaches to intervention fit into two main categories. The "process or deficit approaches" aim to remedy some underlying process deficit with intervention targeted at a neural structure (Polatajko and Cantin, 2005). By contrast, the "functional skill approaches" work on teaching the activities of daily living that the child needs to be able to carry out. Recent meta-analyses demonstrate that the latter category of approaches produces the best therapeutic effect (Blank et al., 2012; Smits-Engelsman et al., 2013). Intervention designs should be addressed not only to the training of neurophysiological procedural circuitry but also to respond to motivations of each subject and to enhance generalization of newly acquired skills and good habits for managing significant cues of daily life, social relationships, and schooling (Polatajko and Cantin, 2005; Sugden and Dunford, 2007). The P4C model (Missiuna et al., 2011) emphasizes the partnership of the occupational therapist with educators and parents to change the life and daily environment of a child; the model focuses on capacity building through collaboration and coaching in context and includes whole class instruction, dynamic performance analysis, and monitoring response to intervention.

Neurobiological habits can be viewed as constrictions of dispositional resources of the agent. Such a perspective on operational habits is, perhaps, more appropriate for so-called "bad" or pathological habits, i.e., obsessions, tics, movement disorders etc. In this article, however, we have emphasized a positive, healthy view of habits because the functions of the human brain are precisely orchestrated on the basis of a huge number of beneficial automatisms that allow us to perform fluently the complex cognitive and motor activities of daily life. Psychoeducation can help young people suffering from DCD to become physically more adept and to liberate their potential for complex thinking, for planning of practical actions and for evaluating the social appropriateness of their behavior.

\section{ACKNOWLEDGMENTS}

This work has been supported by grants from the Government of Navarra and the Fundación Fuentes Dutor (Pamplona, Spain) for research in developmental neurology and neuropsychology (2009-2013).

\section{REFERENCES}

American Psychiatric Association. (2000). Diagnostic and Statistical Manual of Mental Disorders: DSM-IV TR, 4th Edn. Arlington, VA: American Psychiatric Association.

American Psychiatric Association. (2013). Diagnostic and Statistical Manual of Mental Disorders: DSM5, 5th Edn. Washington, DC: American Psychiatric Association.

Bishop, D. V. M. (1998). Development of the Children's Communication Checklist (CCC): a method for assessing qualitative aspects of communicative impairment in children. J. Child Psychol. Psychiatry 39, 879-891. doi: 10.1017/ S0021963098002832

Blank, R., Smits-Engelsman, B., Polatajko, H., and Wilson, P. (2012). European Academy for Childhood Disability: recommendations on the definition, diagnosis and intervention of developmental coordination disorder (long version). Dev. Med. Child Neurol. 54, 54-93. doi: 10.1111/j.1469-8749.2011.04171.x

Bo, J., and Lee, C. M. (2013). Motor skill learning in children with developmental coordination disorder. Res. Dev. Disabil. 34, 2047-2055. doi: 10.1016/j.ridd.2013.03.012

Brossard-Racine, M., Majnemer, A., and Shevell, M. (2011). Exploring the neural mechanisms that underlie motor difficulties in children with Attention Deficit Hyperactivity Disorder. Dev. Neurorehabil. 14, 101-111. doi: 10.3109/17518423.2010.547545

Bruininks, R. H., and Bruininks, B. D. (2005). Bruininks-Oseretsky Test of Motor Proficiency, 2nd Edn. Minneapolis, MN: Pearson Assessment.

Cantell, M. H., Smyth, M. M., and Ahonen, T. P. (1994). Clumsiness in adolescence: educational, motor, and social outcomes of motor delay detected at 5 years. Adapt. Phys. Activ. 11, 115-129.

Crespo-Eguílaz, N., and Narbona, J. (2009). Trastorno de aprendizaje procedimental: características neuropsicológicas. Rev. Neurol. 49, 409-416.

Crespo-Eguílaz, N., Narbona, J., and Magallón, S. (2012). Disfunción de la coherencia central en niños con trastorno de aprendizaje procedimental. Rev. Neurol. 55, 513-519.

Gardner, R. A., and Broman, M. (1979). The Purdue Pegboard normative data on 1334 school children. J. Clin. Child Psychol. 8, 156-162. doi: 10.1080/15374417909532912

Gheysen, F., Van Waelvelde, H., and Fias, W. (2011). Impaired visuo-motor sequence learning in developmental coordination disorder. Res. Dev. Disab. 32, 749-756. doi: 10.1016/j.ridd.2010. 11.005

Gibson, J., Adams, C., Elaine Lockton, E., and Jonathan Green, J. (2013). Social communication disorder outside autism? A diagnostic classification approach to delineating pragmatic language impairment, high functioning autism and specific language impairment. J. Child Psychol. Psychiatry 54, 1186-1197. doi: 10.1111/jcpp. 12079

Gillberg, C. (2003). Deficits in attention, motor control, and perception: a brief review. Arch. Dis. Child. 88, 904-910. doi: 10.1136/adc.88.10.904

Henderson, S. E., and Sugden, D. A. (2007). Movement Assessment Battery for Children, 2nd Edn. London: The Psychological Corporation.

Holck, P., Nettelbladt, U., and Sandberg, A. D. (2009). Children with cerebral palsy, spina bifida and pragmatic language impairment: differences and similarities in pragmatic ability. Res. Dev. Disabil. 30, 942-951. doi: 10.1016/j.ridd.2009.01.008

Kadesjö, B., and Gillberg, C. (1998). Attention deficits and clumsiness in Swedish 7-year-old children. Dev. Med. Child Neurol. 40, 796-804. doi: 10.1111/j.1469-8749.1998.tb12356.x

Kahneman, D., Treisman, A., and Burkell, J. (1983). The cost of visual filtering. J. Exp. Psychol. Hum. Percept. Perform. 9, 510-522. doi: 10.1037/00961523.9.4.510

Leisman, G., Braun-Benjamin, O., and Melillo, R. (2014). Cognitive-motor interactions of the basal ganglia in development. Front. Syst. Neurosci. 8:16. doi: 10.3389/fnsys.2014.00016

Lejeune, C., Catale, C., Willems, S., and Meulemans, T. (2013). Intact procedural motor sequence learning in developmental coordination disorder. Res. Develop. Disab. 34, 1974-1981. doi: 10.1016/j.ridd.2013.03.017

Lingam, R., Hunt, L., Golding, J., Jongmans, M., and Emond, A. (2009). Prevalence of developmental coordination disorder using the DSM-IV at 7 years of age: a UK population-based study. Pediatrics 123, 693-700. doi: 10.1542/peds.2008-1770

Milner, B., Corkin, S., and Teuber, H. L. (1968). Further analysis of the hippocampal amnesic syndrome: 14-year follow-up study of H.M. Neuropsychologia 6, 317-338. doi: 10.1016/00283932(68)90021-3

Missiuna, C., Cairney, J., Pollock, N., Russell, D., Macdonald, K., Cousins, M., et al. (2011). A staged approach for identifying children with developmental coordination disorder from the population. Res. Dev. Disabil. 32, 549-559. doi: 10.1016/j.ridd.2010.12.025

Missiuna, C., Cairney, J., Pollock, N., Campbell, W., Russell, D. J., Macdonald, K., et al. (2014). Psychological distress in children with developmental coordination disorder and attentiondeficit hyperactivity disorder. Res. Dev. Disabil. 35, 1198-1207. doi: 10.1016/j.ridd.2014.01.007

Narbona, J., Crespo-Eguílaz, N., Sánchez-Carpintero, R., and Magallón, S. (in press). Diagnóstico diferencial del trastorno de la comunicación social. Utilidad del Children's Communication ChecklistCCC (Abstract). Rev. Neurol. 58 (Suppl. 3).

Norbury, C. F. (2014). Practitioner review: social (pragmatic) communication disorder conceptualization, evidence and clinical implications. J. Child Psychol. Psychiatry 55, 204-216. doi: 10.1111/jcpp.12154

Noten, M., Wilson, P., Ruddock, S., and Steenbergen, B. (2014). Mild impairments of motor imagery skills in children with DCD. Res. Dev. Disabil. 35, 1152-1159. doi: 10.1016/j.ridd.2014.01.026

Polatajko, H. J., and Cantin, N. (2005). Developmental coordination disorder (dyspraxia): an overview of the state of the art. 
Semin. Pediatr. Neurol. 12, 250-258. doi: 10.1016/j.spen.2005.12.007

Shiffrin, R. M., and Schneider, W. (1977). Controlled and automatic human information processing: II. Perceptual learning, automatic attending and a general theory. Psychol. Rev. 54, 127-190. doi: 10.1037/0033-295X.84.2.127

Smits-Engelsman, B. C. M., Blank, R., Van Der Kaay, A., Mosterd-Van Der Meijs, R., Vlugt-Van Den Brand, E., Polatajko, H. J., et al. (2013). Efficacy of interventions to improve motor performance in children with developmental coordination disorder: a combined systematic review and metaanalysis. Dev. Med. Child Neurol. 55, 229-237. doi: 10.1111/dmcn. 12008

Squire, L. R. (1992). Declarative and non declarative memory: multiple brain systems supporting learning and memory. J. Cogn. Neurosci. 4, 232-243. doi: 10.1162/jocn.1992. 4.3.232

Sugden, D. A., and Dunford, C. D. (2007). The role of theory empiricism and experience in intervention for children with movement difficulties. Disabil. Rehabil. 29, 3-11. doi: 10.1080/09638280600 947542

Treisman, A. M., and Gelade, G. (1980). A feature-integration theory of attention. Cogn.
Psychol. 12, 97-136. doi: 10.1016/0010-0285(80) 90005-5

Volden, J. (2004). Nonverbal learning disability: a tutorial for speech-language pathologist. Am. J. Speech Lang. Pathol. 13, 128-141. doi: 10.1044/1058-0360(2004/014)

Westendorp, M., Hartman, E., Houwen, S., Smith, J., and Visscher, C. (2011). The relationship between gross motor skills and academic achievement in children with learning disabilities. Res. Dev. Disabil. 32, 2773-2779. doi: 10.1016/j.ridd.2011. 05.032

Wilson, B. N., Crawford, S. G., Green, D., Roberts, G. Aylott, A., and Kaplan, B. J. (2009). Psychometric properties of the revised Developmental Coordination Disorder Questionnaire. Phys. Occup. Ther. Pediatr. 29, 182-202. doi: $10.1080 / 01942630902784761$

World Health Organisation. (2013). International Classification of Diseases-11. Proposed criteria for Pragmatic Language Impairment (IDC-11). Geneva: WHO. Available online at: http://www. who.int/classifications/icd/revision/en/index.html [Accessed 31 January 2013].

Zwicker, J. G., Harris, S. R., and Klassen, A. F. (2012). Quality of life domains affected in children with developmental coordination disorder: a systematic review. Child Care Health Dev. 39, 562-580. doi: 10.1111/j.1365-2214.2012. 01379.xcch

Conflict of Interest Statement: The authors declare that the research was conducted in the absence of any commercial or financial relationships that could be construed as a potential conflict of interest.

Received: 28 March 2014; accepted: 03 June 2014; published online: 20 June 2014.

Citation: Crespo-Eguílaz N, Magallón S and Narbona $J$ (2014) Procedural skills and neurobehavioral freedom. Front. Hum. Neurosci. 8:449. doi: 10.3389/fnhum. 2014.00449

This article was submitted to the journal Frontiers in Human Neuroscience.

Copyright (C) 2014 Crespo-Eguílaz, Magallón and Narbona. This is an open-access article distributed under the terms of the Creative Commons Attribution License (CC BY). The use, distribution or reproduction in other forums is permitted, provided the original author(s) or licensor are credited and that the original publication in this journal is cited, in accordance with accepted academic practice. No use, distribution or reproduction is permitted which does not comply with these terms. 